\title{
RESEARCH
}

Open Access

\section{Risk factors for febrile neutropenia and effectiveness of primary prophylaxis with pegfilgrastim in patients with esophageal cancer treated with docetaxel, cisplatin, and 5-fluorouracil}

Yu Ohkura*, Masaki Ueno and Harushi Udagawa

\begin{abstract}
Background: The docetaxel, 5-fluorouracil, and cisplatin (DCF) regimen is an effective form of chemotherapy for advanced esophageal cancer. However, the incidence of adverse events such as febrile neutropenia and hematological toxicity is high.

Methods: Among 937 patients with esophageal cancer at Toranomon Hospital between January 2011 and December 2018, 92 who underwent the DCF regimen as initial treatment were selected. We investigated the risk factors for febrile neutropenia in patients with esophageal cancer treated with DCF regimen and the effectiveness of pegfilgrastim as primary prophylaxis.

Results: Adverse events (CTCAE grade $\geq 3$ ) were observed in 45 of the 92(48.9\%) patients with esophageal cancer treated with an initial DCF regimen. Febrile neutropenia was observed in 20 (21.7\%) patients. Non-use of pegfilgrastim (odds ratio $=16.393 ; 95 \%$ confidence interval 2.049-125.0) as primary prophylaxis was identified as an independent factor predictive of febrile neutropenia. The pegfilgrastim group had a significantly lower incidence of neutropenia than the control group $(9.1 \%$ vs $61.0 \% ; p<0.001)$. The incidence of febrile neutropenia was $3.0 \%$ in the pegfilgrastim group and $32.2 \%$ in the control group $(p=0.001)$. In addition, the incidence of any adverse effect $\geq$ CTCAE grade3 was also significantly lower in the pegfilgrastim group (12.1\% vs $69.5 \% ; p<0.001)$. The reduced/interruption rate of next DCF therapy was $6.1 \%$ in the pegfilgrastim group and $30.5 \%$ in the control group $(p=0.006)$.

Conclusion: This study revealed that the non-use of pegfilgrastim was an independent factor predictive of febrile neutropenia in multivariate analysis. Pegfilgrastim as primary prophylaxis prevents severe neutropenia and febrile neutropenia in patients with esophageal cancer treated with the DCF regimen.
\end{abstract}

Keyword: Pegfilgrastim, Esophageal cancer, DCF regimen, Febrile neutropenia

\footnotetext{
* Correspondence: yu.ohkura107@gmail.com

Department of Gastroenterological Surgery, Toranomon Hospital and

Okinaka Memorial Institute for Medical Research, 2-2-2 Toranomon,

Minato-ku, Tokyo 105-8470, Japan
}

(c) The Author(s). 2019 Open Access This article is distributed under the terms of the Creative Commons Attribution 4.0 International License (http://creativecommons.org/licenses/by/4.0/), which permits unrestricted use, distribution, and reproduction in any medium, provided you give appropriate credit to the original author(s) and the source, provide a link to the Creative Commons license, and indicate if changes were made. The Creative Commons Public Domain Dedication waiver (http://creativecommons.org/publicdomain/zero/1.0/) applies to the data made available in this article, unless otherwise stated. 


\section{Introduction}

Esophageal cancer is one of the most malignant forms of gastrointestinal cancer. The efficacy of chemoradiotherapy and chemotherapy has been demonstrated, and so they are widely used to treat esophageal cancer. Reports have also documented the efficacy of preoperative chemotherapy, which has become the standard form of treatment in Japan. Currently, the standard treatment for stage II and III esophageal cancer is preoperative chemotherapy (cisplatin + 5-fluorouracil [5-FU]: CF regimen) + radical surgery. According to a previous report [1], the 5-year survival rate for cT1-2 cancer is favorable at $79 \%$ following preoperative treatment with the CF regimen. In contrast, the 5-year survival rate for cT3 is poor at $49 \%$, with results showing poorer efficacy of the CF regimen in more advanced cases. A more potent form of preoperative treatment is therefore desirable. For this reason, there has been a growing number of reports on the DCF regimen (docetaxel $+\mathrm{CF}$ ) as this is the more potent form of treatment in recent years [2-4], and the high success rate has attracted attention. On this background, we are currently in the late stages of JCOG1109, a phase 3 comparative clinical trial [5] to clarify the superiority of the preoperative DCF regimen and preoperative $\mathrm{CF}$ chemoradiotherapy compared to the standard preoperative $\mathrm{CF}$ regimen. The DCF regimen, which is more potent than the conventional CF regimen, is associated with high rates of febrile neutropenia, which is viewed as problematic. Although the efficacy of pegfilgrastim for preventing febrile neutropenia has been established in other fields such as hematological diseases, it has not yet been in patients undergoing the DCF regimen as a form of treatment for esophageal cancer. For this reason, in this study, we investigated the risk factors for febrile neutropenia in addition to performing an analysis of pegfilgrastimtreated cases at our hospital and investigated the effectiveness of the DCF regimen.

\section{Materials and methods Study population}

This single-center retrospective study was conducted to evaluate the risk factors for febrile neutropenia in patients with esophageal cancer who were treated with the DCF regimen and the effectiveness of primary prophylaxis with pegfilgrastim. A total of 937 consecutive patients with esophageal cancer were identified from a database that was prospectively constructed between January 2011 and December 2018. Among these, 92 patients were selected according to the following eligibility criteria. Inclusion criteria were histopathologically proven squamous cell carcinoma, esophageal cancer from cervical esophagus to abdominal esophagus, and patients who underwent DCF regimen (100\% dose) as initial treatment; exclusion criteria were any history of esophageal treatment or any history of chemotherapy for other cancer. All patients did not use prophylactic antibiotic therapy. Of these 92 patients, 20 patients who were diagnosed with febrile neutropenia as an adverse event were allocated to the febrile neutropenia (FN) group and the remaining 72 patients were allocated to the non-febrile neutropenia $(\mathrm{N})$ group in study 1 . Of these 92 patients, 33 patients were administered pegfilgrastim as primary prophylaxis and the remaining $59 \mathrm{pa}-$ tients were allocated to the control group in study 2 . We investigated risk factors for febrile neutropenia in patients with esophageal cancer treated using the DCF regimen in study 1 , and the effectiveness of pegfilgrastim as primary prophylaxis of adverse events and the advantage of pegfilgrastim use in DCF therapy in study 2 . We graded all adverse events based on the Common Terminology Criteria for Adverse Events (CTCAE) ver. 4.03 [6], and grade $\geq 3$ events were documented as targets for examination. This study was conducted with approval from the Institutional Review Board of Toranomon Hospital (approval number 1746).

\section{Pretreatment examination}

Pretreatment examination involved physical examination, tumor marker testing, esophagography, upper gastrointestinal endoscopy, colonoscopy, endoscopic ultrasonography, computed tomography, positron emission tomography, and abdominal/neck ultrasonography. We performed gastrostomy before chemotherapy for patients who had dysphagia caused by a bulky esophageal tumor, especially $\mathrm{T} 4$ or suspicious $\mathrm{T} 4$ tumor. Disease stage was classified according to the UICC TNM grading system, 7th edition [7].

\section{Chemotherapy}

All patients in this study received DCF therapy as initial treatment for esophageal cancer. The regimen in this study was docetaxel as 1 -h $75 \mathrm{mg} / \mathrm{m}^{2} \mathrm{I} . \mathrm{V}$. infusion on day 1 , cisplatin $75 \mathrm{mg} / \mathrm{m}^{2} \mathrm{I} . \mathrm{V}$. infusion on day 1 with standard I.V. hydration, and $5-\mathrm{FU} 750 \mathrm{mg} / \mathrm{m}^{2} /$ day by continuous infusion over 5 days. Standard antiemetic support including 5-HT3 antagonists, corticosteroids, and dopamine antagonists was provided. In some cases, pegfilgrastim $(3.6 \mathrm{mg}) 24 \mathrm{~h}$ post-completion of the 5 -FU infusion for all cycles of DCF therapy was administered. The pegfilgrastim was adopted in our hospital in December 2014. Therefore, all these patients of pegfilgrastim group are cases from December 2014.

\section{Statistics}

The risk factors for febrile neutropenia in patients with esophageal cancer treated by DCF therapy were assessed by bivariate logistic regression analysis. Comparisons 
between groups were performed using the Mann-Whitney $U$ test and Pearson's chi-squared test for statistical significance. Variables with significance of $p<0.10$ in univariate analysis were entered into the bivariate logistic analysis. In bivariate analysis, $p<0.05$ was considered significant. All analysis was performed using the Statistical Package for the Social Science (SPSS) software version 19.0J for Windows (SPSS Inc., Chicago, IL).

\section{Results}

Patient characteristics and univariate analysis of the 92 patients

Of the 92 patients, febrile neutropenia was observed in $20(21.7 \%)$ patients. These 20 patients were allocated to the FN group, and the remaining 72 patients were allocated to the $\mathrm{N}$ group. Baseline characteristics of these two groups are summarized in Table 1 . All 92 patients who underwent DCF therapy as initial treatment had a median age of 66.5 years, and $85.9 \%$ of patients were male. Median body mass index of this population was $21.1 \mathrm{~kg} / \mathrm{m}^{2}$. Of 92 patients, 23 patients treated 1 cycle, 61 patients treated 2 cycles, 7 patients treated 3 cycles, and one patient treated 5 cycles. Univariate analysis between the two groups showed a significant difference in the use of pegfilgrastim $(p=0.001)$ and age $(p=0.032)$. Other patient characteristics, pretreatment hematological parameters, and tumor factors showed no significant difference between the two groups.

\section{Study 1: Independent risk factors for febrile neutropenia in multivariate analysis}

Variables with significance of $p<0.10$ in univariate analysis models were entered into the bivariate logistic analysis. Multivariate analysis using the results of univariate analysis (Table 2) was performed for the following selected variables: age, sex, use of pegfilgrastim (yes/no), platelet count, creatinine levels, and cytokeratin 19 fragment (CYFRA). The non-use of pegfilgrastim (odds ratio $[\mathrm{OR}]=16.393$; 95\% confidence interval $[\mathrm{CI}]$ 2.049-125.0; $p=0.008)$ was identified as an independent factor predictive of febrile neutropenia.

\section{Study 2: Adverse events after DCF therapy between the pegfilgrastim and control groups}

Adverse events (CTCAE grade $\geq 3$ ) were observed in 45 of the $92(48.9 \%)$ patients with esophageal cancer treated with initial DCF therapy. The pegfilgrastim group (12.1\%) had a significantly lower incidence of CTCAE grade $\geq 3$ events than the control group $(69.5 \%)(p<0.001)$. The incidence of neutropenia was $9.1 \%$ in the pegfilgrastim group and $61.0 \%$ in the control group, respectively $(p<0.001)$. The incidence of febrile neutropenia was 3.0\% in the pegfilgrastim group and $32.2 \%$ in the control group, respectively $(p=0.001)$. There was no significant difference in the incidence of hyponatremia, anorexia, and nausea between these two groups (Table 3). The rate of classical granulocyte-colony stimulating factor (G-CSF; filgrastim) use was $0 \%$ in the pegfilgrastim group and $52.5 \%$ in the control group, respectively $(p<0.001)$. The rate of reduced/ interruption of next cycle DCF therapy due to adverse effects was $6.1 \%$ in the pegfilgrastim group and $30.5 \%$ in the control group, respectively $(p=0.006)$. The reasons of reduced/ interruption of next cycle DCF therapy were 1 febrile neutropenia and 1 elevation of liver enzyme levels in the pegfilgrastim group, and 12 febrile neutropenia, 5 neutropenia, and 1 acute renal failure in the control group.

\section{Discussion}

In this study, we attempted to identify the factors predictive of febrile neutropenia in patients with esophageal cancer treated using initial DCF therapy. Study 1 shows that the non-use of pegfilgrastim was an independent factor predictive of febrile neutropenia in multivariate analysis. Although several background risk factors were suspected among the risk factors for febrile neutropenia in univariate analysis, only the absence of pegfilgrastim administration remained as an independent risk factor for febrile neutropenia through multivariate analysis. Although the FN group was significantly younger $(p=0.032)$ in univariate analysis, this can be explained by the fact that we performed DCF therapy for young patients at first, but came to perform DCF therapy for the elderly patients after the use of pegfilgrastim was started. In study 2 , the pegfilgrastim group had a significantly lower incidence of both neutropenia and febrile neutropenia than the control group. Including these, the pegfilgrastim group had a significantly lower incidence of entire CTCAE grade $\geq 3$ events. As a consequence, the pegfilgrastim group had less incidence of dose reduction in the following DCF therapy. Therefore, the use of pegfilgrastim can be an option for chemotherapy to achieve the goal of successful completion of scheduled chemotherapy with DCF regimen.

The results of long-term follow-up during the MRCOE2 clinical trial, which allocated patients with resectable esophageal cancer into a neoadjuvant $\mathrm{CF}$ group and a surgery only group, showed that the hazard ratio for overall survival was $0.84(p=0.03)$ in a neoadjuvant $\mathrm{CF}$ group, which was significantly more favorable $[8,9]$. Currently, based on the results of the Japan Clinical Oncology Group (JCOG) 9907 clinical trial [1], the standard treatment for stage II and III esophageal cancer is preoperative chemotherapy (cisplatin + 5-FU: CF regimen) + radical surgery. Furthermore, a meta-analysis compared studies of neoadjuvant chemotherapy to surgery alone reported that the hazard ratio for overall survival was $0.87(p=0.005)$ when all the preoperative chemotherapy groups were compared to the surgery alone group, 
Table 1 Patient characteristics and results of univariate analysis of factors predicting febrile neutropenia

\begin{tabular}{|c|c|c|c|c|}
\hline & $\begin{array}{l}\text { Total } \\
(n=92) \\
n / \text { median }\end{array}$ & $\begin{array}{l}\text { FN group } \\
(n=20)\end{array}$ & $\begin{array}{l}N \text { group } \\
(n=72)\end{array}$ & $p$ value \\
\hline \multicolumn{5}{|l|}{ Patients characteristics } \\
\hline Age (years) & 66.5 & 58.0 & 67.0 & 0.032 \\
\hline Sex (male/ female) & $79 / 13$ & $17 / 3$ & $62 / 10$ & n.s. \\
\hline PS $(0 / 1 / 2)$ & $71 / 19 / 2$ & $16 / 3 / 1$ & $55 / 16 / 1$ & n.s. \\
\hline Alcohol (yes/no) & $83 / 9$ & $18 / 2$ & $65 / 7$ & n.s. \\
\hline Smoking (yes/no) & $79 / 13$ & $17 / 3$ & $62 / 10$ & n.s. \\
\hline $\begin{array}{l}\text { Brinkman index } \\
(<600 / \geq 600)\end{array}$ & $40 / 52$ & $6 / 14$ & $34 / 38$ & n.s. \\
\hline Malignancy & $83 / 9$ & $19 / 1$ & $64 / 8$ & n.s. \\
\hline $\begin{array}{l}\text { Use of pegfilgrastim } \\
\text { (yes/no) }\end{array}$ & $33 / 59$ & $1 / 19$ & $32 / 40$ & 0.001 \\
\hline $\begin{array}{l}\text { Cardiovascular disease } \\
\text { (yes/no) }\end{array}$ & $6 / 86$ & $1 / 19$ & $5 / 67$ & n.s. \\
\hline $\begin{array}{l}\text { Pulmonary disease } \\
\text { (yes/no) }\end{array}$ & $8 / 84$ & $3 / 17$ & $5 / 67$ & n.s. \\
\hline BMI & 21.1 & 20.8 & 21.1 & n.s. \\
\hline \multicolumn{5}{|c|}{ Pretreatment hematological items } \\
\hline $\mathrm{WBC}\left(\times 10^{3} / \mathrm{mL}\right)$ & 6.50 & 5.95 & 6.70 & n.s. \\
\hline Neutrophils $\left(\times 10^{3} / \mathrm{mL}\right)$ & 4.22 & 3.66 & 4.68 & n.s. \\
\hline $\mathrm{Hb}(\mathrm{g} / \mathrm{dL})$ & 13.5 & 14.0 & 13.4 & n.s. \\
\hline Plt $\left(\times 10^{3} / \mathrm{mL}\right)$ & 267.0 & 232.0 & 274.0 & 0.075 \\
\hline $\mathrm{TP}(\mathrm{g} / \mathrm{dL})$ & 7.1 & 7.2 & 7.1 & n.s. \\
\hline Alb (g/dL) & 3.9 & 4.0 & 3.8 & n.s. \\
\hline BUN (mg/dL) & 13.0 & 13.0 & 13.0 & n.s. \\
\hline Cre (mg/dL) & 0.75 & 0.70 & 0.77 & 0.058 \\
\hline AST (IU/L) & 20.0 & 21.5 & 19.0 & n.s. \\
\hline ALT (IU/L) & 14.0 & 18.5 & 13.0 & n.s. \\
\hline LDH (IU/L) & 181.0 & 173.5 & 181.0 & n.s. \\
\hline ALP (IU/L) & 199.0 & 196.0 & 199.0 & n.s. \\
\hline y s. (IU/L) & 38.0 & 38.5 & 38.0 & n.s. \\
\hline Bil (mg/dL) & 0.70 & 0.75 & 0.60 & n.s. \\
\hline CRP $(\mathrm{mg} / \mathrm{dL})$ & 0.10 & 0.05 & 0.10 & n.s. \\
\hline $\mathrm{Na}(\mathrm{mmol} / \mathrm{L})$ & 142 & 142 & 142 & n.s. \\
\hline $\mathrm{K}(\mathrm{mmol} / \mathrm{L})$ & 4.2 & 4.3 & 4.2 & n.s. \\
\hline $\mathrm{Cl}(\mathrm{mmol} / \mathrm{L})$ & 105.0 & 105.0 & 105.0 & n.s. \\
\hline HbA1c (\%) & 5.6 & 5.6 & 5.6 & n.s. \\
\hline CEA $(\mu \mathrm{g} / \mathrm{L})$ & 2.8 & 2.5 & 2.8 & n.s. \\
\hline CA19-9 (U/mL) & 11.0 & 8.0 & 12.0 & n.s. \\
\hline $\mathrm{SCC}(\mu \mathrm{g} / \mathrm{L})$ & 1.3 & 1.2 & 1.3 & n.s. \\
\hline CYFRA ( $\mu \mathrm{g} / \mathrm{L})$ & 1.9 & 2.3 & 1.8 & 0.084 \\
\hline p53 U/mL & 0.69 & 0.69 & 0.69 & n.s. \\
\hline
\end{tabular}

Table 1 Patient characteristics and results of univariate analysis of factors predicting febrile neutropenia (Continued)

\begin{tabular}{|c|c|c|c|c|}
\hline & $\begin{array}{l}\text { Total } \\
(n=92) \\
n / \text { median }\end{array}$ & $\begin{array}{l}\text { FN group } \\
(n=20)\end{array}$ & $\begin{array}{l}N \text { group } \\
(n=72)\end{array}$ & $p$ value \\
\hline \multicolumn{5}{|l|}{ Tumor factors } \\
\hline c T factor (7th) & & & & n.s. \\
\hline $1 a / 1 b$ & $2 / 7$ & $0 / 0$ & $2 / 7$ & \\
\hline 2 & 17 & 4 & 13 & \\
\hline 3 & 50 & 14 & 36 & \\
\hline $4 a$ & 5 & 2 & 3 & \\
\hline $4 b$ & 11 & 0 & 11 & \\
\hline c N factor (7th) & & & & n.s. \\
\hline 0 & 9 & 2 & 7 & \\
\hline 1 & 33 & 6 & 27 & \\
\hline 2 & 38 & 9 & 29 & \\
\hline 3 & 10 & 3 & 7 & \\
\hline 4 & 2 & 0 & 2 & \\
\hline c stage (7th) & & & & n.s. \\
\hline I (IB) & 3 & 0 & 3 & \\
\hline$\|(\|\mathrm{A},\| \mathrm{B})$ & $6 / 10$ & $3 / 2$ & $3 / 8$ & \\
\hline III (IIIA, IIIB, IIIC) & 21/13/16 & $5 / 2 / 2$ & $16 / 11 / 14$ & \\
\hline IV & 23 & 6 & 17 & \\
\hline Tumor localization & & & & n.s. \\
\hline Ut & 10 & 1 & 9 & \\
\hline Mt & 50 & 12 & 38 & \\
\hline Lt & 17 & 5 & 12 & \\
\hline $\mathrm{Ae}$ & 2 & 0 & 2 & \\
\hline EGJ & 13 & 2 & 11 & \\
\hline
\end{tabular}

Abbreviations: $P S$ performance status, $B M I$ body mass index, $W B C$ white blood cell count, $\mathrm{Hb}$ hemoglobin, Plt platelet count, TP total protein, Alb albumin $B U N$ blood urea nitrogen, $C r e$ creatinine, AST aspartate transaminase, $A L T$ alanine aminotransferase, $L D H$ lactate dehydrogenase, $A L P$ alkaline phosphatase, GTP glutamyl transpeptidase, Bil bilirubin, CRP c-reactive protein, Na sodium, $K$ potassium, $C$ chloride, CEA carcinoembryonic antigen, CA19-9 carbohydrate antigen 19-9, SCC squamous cell carcinoma antigen, CYFRA cytokeratin-19 fragments, Ut upper thoracic esophagus, Mt middle thoracic esophagus, $L t$ lower thoracic esophagus, Ae abdominal esophagus, EGJ esophagogastric junction

suggesting the efficacy of preoperative chemotherapy [10]. Meanwhile, neoadjuvant chemoradiotherapy has been widely performed in Western countries; however, the survival of neoadjuvant chemotherapy followed by surgery in Japanese study appears not inferior to the western results of neoadjuvant CRT. The JCOG 9907 clinical trial subgroup analysis results [1] showed that the 5-year survival rate for cT1-2 cancer is favorable at $79 \%$ when treated with the CF regimen preoperatively. By contrast, the 5-year survival rate for cT3 is poor at $49 \%$, with results showing poorer efficacy of the regimen in more advanced cases. A more potent form of preoperative treatment is therefore desirable. There have been increasing numbers of reports 
Table 2 Results of multivariate analysis of the factors predicting febrile neutropenia

\begin{tabular}{llll}
\hline Variables & Odds ratio & $95 \% \mathrm{Cl}$ & $p$ value \\
\hline Non-use of pegfilgrastim & 16.393 & $2.049-125.0$ & 0.008 \\
\hline
\end{tabular}

of using the DCF regimen (docetaxel + CF regimen) in practice as this more potent form of treatment in recent years [2-4], and the high success rate has attracted much attention. Against this background, we are currently in the advanced stages of a phase 3 comparative clinical trial JCOG1109 [5] to verify the superiority of the preoperative DCF regimen and preoperative CF chemoradiotherapy compared to the preoperative $\mathrm{CF}$ regimen, which is the standard form of treatment. The DCF regimen, which is more potent than the conventional CF regimen, causes high rates of febrile neutropenia, which is viewed as

Table 3 Comparison of adverse events between the two groups

\begin{tabular}{|c|c|c|c|c|}
\hline & $\begin{array}{l}\text { Total } \\
(n=92)\end{array}$ & $\begin{array}{l}\text { Pegfilgrastim } \\
(n=33)\end{array}$ & $\begin{array}{l}\text { Control } \\
(n=59)\end{array}$ & $p$ value \\
\hline CTCAE $\geq$ grade 3 & & & & $<0.001$ \\
\hline Yes & 45 & 4 & 41 & \\
\hline No & 47 & 29 & 18 & \\
\hline CTCAE grade 4 & & & & 0.018 \\
\hline Yes & 9 & 0 & 9 & \\
\hline No & 83 & 33 & 50 & \\
\hline Neutropenia & & & & $<0.001$ \\
\hline Yes & 39 & 3 & 36 & \\
\hline No & 53 & 30 & 23 & \\
\hline Febrile neutropenia & & & & 0.001 \\
\hline Yes & 20 & 1 & 19 & \\
\hline No & 72 & 32 & 40 & \\
\hline Hyponatremia & & & & 0.643 \\
\hline Yes & 4 & 1 & 3 & \\
\hline No & 88 & 32 & 56 & \\
\hline Anorexia & & & & 0.216 \\
\hline Yes & 7 & 1 & 6 & \\
\hline No & 85 & 32 & 53 & \\
\hline Nausea & & & & 0.285 \\
\hline Yes & 2 & 0 & 2 & \\
\hline No & 90 & 33 & 57 & \\
\hline G-CSF (filgrastim) use & & & & $<0.001$ \\
\hline Yes & 31 & 0 & 31 & \\
\hline No & 61 & 33 & 28 & \\
\hline Next cycle DCF therapy & & & & 0.006 \\
\hline Planed administration & 72 & 31 & 41 & \\
\hline Reduced/interruption & 20 & 2 & 18 & \\
\hline
\end{tabular}

problematic. Febrile neutropenia is an adverse reaction to anticancer drug treatment that may have serious outcomes, and primary prophylaxis with pegfilgrastim is recommended when using regimens with a high rate of febrile neutropenia onset of $\geq 20 \%$. Going forward, based on the results of the JCOG 1109 clinical trial [5], the DCF regimen may become a standard form of treatment, so it is needed before this occurs to rapidly establish an effective modality of prophylaxis for febrile neutropenia. For this reason, we performed an analysis of pegfilgrastim-treated cases at our hospital and investigated its effectiveness in the DCF regimen.

In September 2014, conventional G-CSF was pegylated to prolong its serum half-life, yielding pegfilgrastim; a single administration at a dose of $3.6 \mathrm{mg}$ during each cycle is sufficient to prevent febrile neutropenia. Although the efficacy of pegfilgrastim for preventing febrile neutropenia has been demonstrated in other fields, such as hematological diseases, there are few reports assessing it in patients undergoing the DCF regimen as a form of treatment for esophageal cancer [2-4]. In this study, the administration of pegfilgrastim in practice resulted in a significantly lower incidence of adverse drug reactions ranked as CTCAE grade $\geq 3$, and significantly fewer patients had neutropenia $(p<0.001)$ and febrile neutropenia $(p=0.001)$ in particular. No changes were observed in terms of other adverse events, such as hyponatremia, anorexia, and nausea. And also, we were able to decrease the rate of reduced/ interruption of next cycle DCF therapy due to adverse effects by using the pegfilgrastim from 30.5 to $6.1 \%$, significantly $(p=0.006)$. There were no patients who administered additional classical G-CSF in the pegfilgrastim group; meanwhile, these occurred in 31 out of 59 subjects (52.5\%).

In this study, of 92 patients, 77 patients underwent esophagectomy after neoadjuvant DCF therapy. Other 15 patients did not undergo esophagectomy and received only chemotherapy included DCF therapy. We usually perform esophagectomy about 3 to 4 weeks after the last cycle of DCF therapy. Of all patients, 67 patients $(72.8 \%)$ underwent 3-field esophagectomy in this study. And also, there were no significant differences in surgical complications between two groups with or without severe neutropenia/ febrile neutropenia $(p=0.722)$ (data were not shown).

The major limitations of our study are the singlecenter, retrospective design and the small number of patients investigated. However, the current data are based on a prospectively collated database for consecutive patients over a relatively short period. An external validation study involving a sufficient number of patients would be needed to confirm our observations; a multicenter study with a larger number of cases is also warranted. 


\section{Conclusions}

The non-use of pegfilgrastim after the first cycle of the DCF regimen to treat esophageal cancer was found to be an independent risk factor for febrile neutropenia, and pegfilgrastim prevented the onset of severe neutropenia and febrile neutropenia. And also, the use of pegfilgrastim can be an option for chemotherapy to achieve the goal of successful completion of scheduled chemotherapy with DCF regimen. Going forward, although the DCF regimen is not yet established as a form of treatment for esophageal cancer, administration of pegfilgrastim as primary prophylaxis during the DCF regimen should be effective.

\section{Abbreviations}

5FU: 5-Fluorouracil; cCR: Clinical complete response; CT: Computed tomography; DCF: Docetaxel, cisplatin, and 5-fluorouracil; DSS: Disease-specific survival; NACRT: Neoadjuvant chemoradiotherapy; NACT: Neoadjuvant chemotherapy; OS: Overall survival; pCR: Pathologic complete response; PET: Positron emission tomography; RECIST: Response Evaluation Criteria In Solid Tumors; RFS: Recurrence-free survival

\section{Acknowledgements}

None

\section{Authors' contributions}

$\mathrm{YO}, \mathrm{MU}$, and $\mathrm{HU}$ designed the study and wrote the paper. $\mathrm{YO}, \mathrm{MU}$, and $\mathrm{HU}$ drafted the article, revised it critically for important intellectual content, and gave the final approval for the content. YO, MU, and $\mathrm{HU}$ created the study materials or recruited the patients. All authors read and approved the final manuscript.

\section{Funding}

None declared

\section{Availability of data and materials}

Some advocates of clinical data sharing are keen for data to be shared in agreed, standardized formats to facilitate its automated reuse for statistical analysis.

\section{Ethics approval and consent to participate}

This study was approved by the Institutional Review Board of Toranomon Hospital.

\section{Consent for publication}

Informed consent was obtained from these patients for publication of this report.

\section{Competing interests}

The authors declare that they have no competing interests.

Received: 29 March 2019 Accepted: 8 July 2019

Published online: 17 July 2019

\section{References}

1. Ando $\mathrm{N}$, Kato $\mathrm{H}$, Igaki $\mathrm{H}$, et al. A randomized trial comparing postoperative adjuvant chemotherapy with cisplatin and 5-fluorouracil versus preoperative chemotherapy for localized advanced squamous cell carcinoma of the thoracic esophagus (JCOG9907). Ann Surg Oncol. 2012;19:68-74.

2. Takahashi $\mathrm{K}$, Inose $\mathrm{R}$, Takahashi $\mathrm{M}$, et al. Examination of primary prophylactic effect of pegfilgrastim for preventing febrile neutropenia in esophageal cancer patients undergoing docetaxel + cisplatin + 5-fluorouracil therapy. Jpn J Pharm Health Care Sci. 2017:46:336-43.

3. Yoshida Y, Komori K, Aoki M, et al. Efficacy of pegfilgrastim administration in patients with esophageal cancer treated with docetaxel, cisplatin, and 5-fluorouracil. Pharmazie. 2018;73:613-6.
4. Ferri LE, Abes S, Alcindor T, et al. Perioperative docetaxel, cisplatin, and 5fluorouracil (DCF) for locally advanced esophageal and gastric adenocarcinoma: a multicenter phase II trial. Ann Oncol. 2012;23:1512-7.

5. Nakamura K, Kato K, Igaki H, et al. Tree-arm phase III trial comparing cisplatin plus 5-FU (CF) versus docetaxel, cisplatin plus 5-FU (DCF) versus radiotherapy with CF (CF-RT) as preoperative therapy for locally advanced esophageal cancer (JCOG1109, NEXT study). Jpn J Clin Oncol. 2013;43:752-5.

6. National Cancer Institute, National Institutes of Health, U.S. Department of Health and Human Services. Common Terminology Criteria for Adverse Events (CTCAE) Version 4.03. Available from URL: https://www.eortc.be/ services/doc/ctc/CTCAE_4.03_2010-06-14_QuickReference_5x7.pdf.

7. Sobin LH, Gospodarowicz MK, Wittekind C. International Union Against Cancer. Oesophagus including oesophagogastric junction. "TNM classification of malignant tumours". West Sussex: Wiley-Blackwell; 2009. p. 66-72.

8. In Medical Research Council Oesophageal Cancer Working Group. Surgical resection with or without preoperative chemotherapy in oesophageal cancer: a randomised controlled trial. Lancet. 2002;359(9319):1727-33.

9. Allum WH, Stenning SP, Bancewicz J, et al. Long-term results of a randomized trial of surgery with or without preoperative chemotherapy in esophageal cancer. J Clin Oncol. 2009;27(30):5062-7.

10. Sjoquist KM, Burmeister BH, Smithers BM, et al. Survival after neoadjuvant chemotherapy or chemoradiotherapy for resectable oesophageal carcinoma: an updated meta-analysis. Lancet Oncol. 2011;12(7):681-92.

\section{Publisher's Note}

Springer Nature remains neutral with regard to jurisdictional claims in published maps and institutional affiliations.

\section{Ready to submit your research? Choose BMC and benefit from:}

- fast, convenient online submission

- thorough peer review by experienced researchers in your field

- rapid publication on acceptance

- support for research data, including large and complex data types

- gold Open Access which fosters wider collaboration and increased citations

- maximum visibility for your research: over $100 \mathrm{M}$ website views per year

At BMC, research is always in progress.

Learn more biomedcentral.com/submissions 